\title{
High costs and burden of illness in acute rhinosinusitis: real-life treatment patterns and outcomes in Swedish primary care
}

\section{*Pär Stjärne ${ }^{a}$, Peter Odebäck ${ }^{b}$, Björn Ställbergc, Johan Lundberg d, Petter Olsson ${ }^{a}$}

\author{
a Department of Clinical Science, Intervention and Technology, Division of Otorhinolaryngology, Karolinska Institute, Stockholm, Sweden \\ b Skagern Primary Health Care Centre, Gullspång and Capio Primary Health Care Units, Göteborg, Sweden \\ Department of Public Health and Caring Science, Family Medicine and Clinical Epidemiology, Uppsala, Sweden \\ 'Outcomes Research, MSD Sweden, Sollentuna, Sweden
}

Received 2nd September 2011; revised 9th December 2011; accepted 12th December 2011; online 20 th February 2012

\begin{abstract}
Background: Few studies have investigated the impact of acute rhinosinusitis on disease-specific quality of life, and disease costs have not been studied previously in Scandinavia.

Aims: To study symptoms, treatment patterns, quality of life and costs in adults with acute rhinosinusitis.

Methods: This was an observational study in primary care. Patients aged 18-80 years seeking care for acute rhinosinusitis were evaluated using the Major Symptom Score (MSS) on days 0 and 15. Recommended and used treatments, quality of life and costs were assessed by questionnaires including EQ-5DTM and a visual analogue scale (VAS) on the same days.

Results: 150 patients were enrolled; 143 provided follow-up data. The proportion of MSS responders was $91 \%$. Mean MSS decreased from 8.4 on day $0(\mathrm{~N}=150)$ to 1.9 on day $15(\mathrm{~N}=143)$. Patients reporting pain/discomfort and problems with usual activities decreased from $88.4 \%$ to $31.5 \%$ and from $43.2 \%$ to $1.4 \%$, respectively, and mean VAS increased from 58.7 to 79.5 . Intranasal corticosteroids were the most recommended and/or prescribed drugs. Total cost for an episode was 10,260 SEK $(€ 1,102)$, of which $75 \%$ were indirect costs.

Conclusions: With treatment dominated by intranasal corticosteroids, a high proportion of responders and good symptom relief were seen. Acute rhinosinusitis seems to cause a high burden on quality of life and also a high cost for society.

(C) 2012 Primary Care Respiratory Society UK. All rights reserved.

P Stjärne et al. Prim Care Respir J 2012; 21(2): 174-179

http://dx.doi.org/10.4104/pcrj.2012.00011
\end{abstract}

Keyw ords EQ-5D ${ }^{\mathrm{TM}}$, Major Symptom Score, primary care, rhinosinusitis, observational study, visual analogue scale, adults

See linked editorial by Friedlander on pg 130

The full version of this paper, with online Appendices,

is available at www.thepcrj.org

\section{Introduction}

Symptoms consistent with acute rhinosinusitis are common clinical problems in primary care practice. In Europe, 1-2\% of all patient visits to physicians in primary care are for suspected acute sinusitis. ${ }^{1}$ The high number of visits to physicians translates to a high burden on the healthcare system. In 2000 the direct costs in the United States were estimated to be nearly $\$ 6$ billion. ${ }^{2,3}$

According to current European guidelines, the recommended treatment for mild acute rhinosinusitis is symptomatic, with nasal steroids advised in moderate cases ${ }^{4,5}$ Antibiotics should only be added if severe symptoms are present (e.g. fever $>38^{\circ} \mathrm{C}$, severe pain). The evidence for the efficacy of decongestants in the treatment of acute rhinosinusitis in adults is poor, and decongestants only have a grade $\mathrm{D}$ recommendation. ${ }^{4,5}$

According to recent estimates, bacterial infection is present in $\leq 50 \%$ of patients with symptoms of acute rhinosinusitis ${ }^{6,7}$ and may be as low as $0.5-2 \% .{ }^{8}$ Several studies have shown that antibiotics commonly used in Sweden are of limited value in the management of patients with mild to moderate acute rhinosinusitis. ${ }^{9-11} \mathrm{An}$ increase in antibiotic resistance has also been observed among Streptococcus pneumoniae isolates globally, particularly to amoxicillin and other beta-lactam antibiotics. ${ }^{12}$ Despite this, antibiotics have previously been estimated to be

* Corresponding author: Professor Pär Stjärne, Department of Otorhinolaryngology, Karolinska University Hospital, 17176, Stockholm, Sweden. Tel: +46-707-250749 E-mail: par.stjarne@karolinska.se 
prescribed to more than $90 \%$ of adult patients seen for acute rhinosinusitis in the UK. ${ }^{13}$ The proportion receiving antibiotics in Scandinavia has also been high. ${ }^{14}$ However, a recent questionnaire study performed in the Netherlands showed that current treatment patterns might have changed, as the antibiotic prescription frequency in that study was $20 \%$ and $34 \%$ for mild and moderate acute rhinosinusitis, respectively. ${ }^{15}$

Few studies investigating the impact of acute rhinosinusitis on disease-specific quality of life have been performed and generic quality of life data are limited. ${ }^{16}$ Furthermore, to our knowledge, the costs for acute rhinosinusitis have not previously been investigated in Scandinavia.

The purpose of this study was to investigate the treatment patterns in acute rhinosinusitis in primary care and to increase knowledge of the disease population, symptoms, quality of life and costs.

\section{Methods}

\section{Study design and patients}

This was a prospective non-interventional observational study in adults with acute rhinosinusitis performed at 11 Swedish primary care practices from November 2008 to December 2009. The study protocol was approved by the ethics committee in Stockholm, Sweden, and written informed consent was obtained from all patients before inclusion in the study.

The study protocol did not provide any restrictions for the treatment of acute rhinosinusitis. At the discretion of the investigator, medical treatment was prescribed in accordance with local standard practice, i.e. the chosen treatment by the investigator of each centre in this study for each patient with acute rhinosinusitis, as defined by the inclusion/exclusion criteria.

The primary objective and endpoint was to estimate the proportion of responders according to the Major Symptom Score (MSS) for patients with acute rhinosinusitis. A responder was predefined in the study protocol as a patient who improved in the MSS by at least $30 \%$ from day 0 to day 15 (preferably \pm 2 days). Secondary objectives and endpoints were: (1) to estimate the changes in MSS and individual item scores from day 0 to day 15 (preferably \pm 2 days); (2) to describe current drug treatment patterns; (3) to describe the health-related quality of life status

\begin{tabular}{|c|c|}
\hline $\begin{array}{c}\text { Day 0 } \\
\text { Clinic visit } \\
\mathrm{N}=150\end{array}$ & $\begin{array}{l}\text { ay } 15 \pm 2 \\
\text { one follow-up } \\
N=143\end{array}$ \\
\hline $\begin{array}{l}\text { - Inclusion/exclusion criteria } \\
\text { - } \text { Demographic and baseline data } \\
\text { - Relevant medical history } \\
\text { - } \text { MSS } \\
\text { - EQ- } 5 \mathrm{D}^{\mathrm{TM}} \text {, including VAS } \\
\text { - Productivity, health care utilisation } \\
\text { - Recomment questionnaire } \\
\text { - Recommended/prescribed } \\
\text { medications }\end{array}$ & $\begin{array}{l}\text { - } M S S \\
\text { - } E Q-5 D^{\mathrm{T} M} \text {, including VAS } \\
\text { - Productivity, health care } \\
\text { utilisation and treatment } \\
\text { questionnaire } \\
\text { - Used medications }\end{array}$ \\
\hline
\end{tabular}

associated with acute rhinosinusitis and related to the severity of the symptoms; and (4) to estimate the total costs related to episodes of acute rhinosinusitis and to the severity of the symptoms.

The study design is shown in Figure 1. Patients were recruited from the pool of patients attending the practice seeking medical treatment on an outpatient basis. Inclusion was based on duration of symptoms ( $\geq 7$ but $\leq 28$ days) and severity of acute rhinosinusitis (MSS $\geq 5$ but $\leq 12$; see Questionnaires and data collection forms, available as online appendices at www.thepcrj.org). ${ }^{10}$ Exclusion criteria included signs and symptoms suggestive of fulminant bacterial acute rhinosinusitis (fever $\geq 38.3^{\circ} \mathrm{C}$ or $\geq 38.5^{\circ} \mathrm{C}$ if a digital thermometer was not available, persistent severe unilateral facial or tooth pain, facial swelling, dental involvement or a worsening of symptoms after initial improvement).

On the inclusion day (day 0), questionnaires were completed by the patients, and demographic data, relevant medical history and recommended and/or prescribed medications were recorded by the investigator in a case report form. On day 15 (preferably \pm 2 days), a telephone follow-up was conducted by an independent medically-qualified person.

Questionnaires and data collection

Major Symptom Score (MSS)

The MSS ${ }^{17}$ was the sum of scores for the five major symptoms rhinorrhoea, postnasal drip, nasal congestion/stuffiness, sinus headache and facial pain/pressure/tenderness (see Appendix 1, available online at www.thepcrj.org). Each symptom was graded as 0 (none), 1 (mild), 2 (moderate) or 3 (severe). The patients were asked to grade symptoms related to acute rhinosinusitis that they had experienced during $12 \mathrm{~h}$ prior to the visit on day 0 and to the follow-up telephone call on day 15 . The questionnaire was reviewed by the investigator on day 0

Quality of life

Quality of life was assessed by the EQ-5DTM (see Appendix 2 online). ${ }^{18}$ The patients were asked to grade their health status on days 0 and 15. Mobility, self-care, usual activities, pain/discomfort and anxiety/depression were graded as 'none/no problems', 'moderate/some problems' or 'severe/extreme problems'. The patients also indicated their health status on a visual analogue scale (VAS) where 0 indicated worst conceivable status and 100 indicated best conceivable status.

\section{Costs}

The productivity, healthcare utilisation and treatment questionnaire completed on days 0 and 15 captured information on (1) outpatient visit and institutional care; (2) travel to the doctor; (3) employment status and absence due to illness; and (4) use of medications for acute rhinosinusitis (see Appendix 3 online). For the day 0 questionnaire, patients were asked to consider a recall period of 7 days. Thus the cost of 'one episode' of acute rhinosinusitis was all costs due to acute rhinosinusitis 7 days before the inclusion visit and 15 days after, a total of 22 days. To give productivity, transport and healthcare utilisation 
monetary values, unit costs were assigned. For cost of medication, as a principle, the cost of the smallest pack(s) corresponding to the reported use was used. An exception was made for painkillers (non-steroidal anti-inflammatory drugs, paracetamol, etc) as it was assumed that patients would have a supply of painkillers at home and thus only the daily cost of painkillers was used to estimate cost. Unit costs for healthcare resource use, transport and medication were based on published price lists. Unit cost for productivity was derived from the mean annual income. Direct cost was the sum of costs for outpatient visits and institutional care, travel to the doctor and use of medications. Transportation costs from patients' visits up until and on day 0 were included. Indirect cost was the sum of costs for loss of productivity as derived from answers to questions on employment status, reduced productivity and absence due to illness. Total cost was the sum of direct and indirect costs.

The questionnaire was completed by the patient after information about the disease by the investigator.

\section{Statistical methods}

All data were summarised by means of descriptive statistics and a $95 \%$ confidence interval $(\mathrm{Cl})$ for the proportion of responders was calculated. Pearson correlation was used to analyse EQ5D'M , VAS and total cost relationship to MSS.

For the presentation of descriptive statistics of EQ-5DTM and cost variables, the MSS symptom severity classes were defined as low (MSS 5-6), mid (MSS 7-9) and high (MSS 10-12).

\section{Results}

\section{Studied population}

A total of 150 patients were enrolled, of whom 143 provided data at follow-up (including six patients with MSS outside the prespecified MSS range).

Demographic data and main background characteristics are summarised in Table 1. The mean age was 45.1 years and $76.7 \%$ of the patients were female; $20.4 \%$ of the patients were current smokers and $2.7 \%$ were former smokers. The most common current or past medical history conditions were asthma (29.9\%) and seasonal allergic rhinitis (26.5\%). Sleep was impaired in approximately half of the patients due to the current episode of acute rhinosinusitis.

\section{Primary endpoint}

The proportion of responders (i.e. the proportion of patients in whom MSS improved by at least $30 \%$ from day 0 to day 15 ) was 90.9\% (95\% Cl: $85.0 \%-95.1 \%)$.

\section{Secondary endpoints}

\section{Mean change in MSS from day 0 to day 15}

Mean (SD) MSS decreased from 8.4 (2.3) on day 0 to 1.9 (2.2) on day 15. The mean (SD) change from baseline to day 15 in MSS was -6.4 (2.8). Ten patients showed no or limited change in MSS (0, 1 or -1$)$. The mean (SD) change in individual MSS items were -1.5 (1.0) for sinus headache, -1.5 (1.0) for nasal congestion/ stuffiness, $-1.3 \quad$ (1.0) for facial
Table 1. Demographic data and main background characteristics

\begin{tabular}{|c|c|c|}
\hline Variable & Statistic & Result \\
\hline \multicolumn{3}{|l|}{ Demographic data } \\
\hline Age (years) & $\begin{array}{l}\text { No. of observations } \\
\text { Mean (SD) } \\
\text { Min, Max }\end{array}$ & $\begin{array}{l}150 \\
45.1(14.5) \\
18,80 \\
\end{array}$ \\
\hline Gender & $\begin{array}{l}\text { No. of observations } \\
\text { Male } \\
\text { Female }\end{array}$ & $\begin{array}{l}150 \\
35(23.3 \%) \\
115(76.7 \%) \\
\end{array}$ \\
\hline Smoker & $\begin{array}{l}\text { No. of observations } \\
\text { Non } \\
\text { Yes, current } \\
\text { Yes, former }\end{array}$ & $\begin{array}{l}147 \\
113(76.9 \%) \\
30(20.4 \%) \\
4(2.7 \%)\end{array}$ \\
\hline \multicolumn{3}{|l|}{ Medical history } \\
\hline Asthma & $\begin{array}{l}\text { No. of observations } \\
\text { No } \\
\text { Yes }\end{array}$ & $\begin{array}{l}147 \\
103(70.1 \%) \\
44(29.9 \%) \\
\end{array}$ \\
\hline Seasonal allergic rhinitis & $\begin{array}{l}\text { No. of observations } \\
\text { No } \\
\text { Yes }\end{array}$ & $\begin{array}{l}147 \\
108(73.5 \%) \\
39(26.5 \%) \\
\end{array}$ \\
\hline Perennial allergic rhinitis & $\begin{array}{l}\text { No. of observations } \\
\text { No } \\
\text { Yes }\end{array}$ & $\begin{array}{l}147 \\
132(89.8 \%) \\
15(10.2 \%)\end{array}$ \\
\hline Sleep impairment* & $\begin{array}{l}\text { No. of observations } \\
\text { No } \\
\text { Yes }\end{array}$ & $\begin{array}{l}146 \\
62(42.5 \%) \\
84(57.5 \%)\end{array}$ \\
\hline
\end{tabular}

*The question on day 0 was: "Is the patient's sleep impaired due to the current episode of acute rhinosinusitis?"

$\mathrm{SD}=$ standard deviation.

pain/pressure/tenderness, -1.2 (0.9) for postnasal drip and -0.9 (1.1) for rhinorrhoea.

\section{Recommended and/or prescribed medications and use of medications}

Intranasal corticosteroids were the most recommended/prescribed medications (91\%), followed by antibiotics (60\%) and decongestant tablets (27\%) (Table 2 and Figure 2).

\section{EQ-5D ${ }^{\text {TM }}$ dimensions and VAS}

On day 0 , pain/discomfort was reported by $88.4 \%$ of patients and problems with usual activities by $43.2 \%$. Extreme pain/discomfort

\section{Table 2. Treatment pattern of acute rhinosinusitis}

\begin{tabular}{lll} 
Category & $\begin{array}{l}\text { Recommended and/ } \\
\text { or prescribed }(\mathrm{N})^{*}\end{array}$ & $\begin{array}{l}\text { Used } \\
(\mathrm{N}) \dagger\end{array}$ \\
\hline Nasal corticosteroid & 137 & 127 \\
\hline Antibiotic & 90 & 103 \\
\hline Decongestant tablet & 41 & 49 \\
\hline Antihistamines (tablet) & 22 & 6 \\
\hline Pain killer & 21 & 21 \\
\hline Decongestant spray & 8 & 12 \\
\hline Other $\neq$ & 7 & 24 \\
\hline *Data from day 0 in the case report form (N=150). & \\
†Data from day 15 in the productivity, healthcare utilisation and \\
treatment questionnaire ( $\mathrm{N}=143$ ). \\
$\begin{array}{l}\text { †For the category 'other', it was possible to fill in two different treatments; } \\
\text { if two treatments were filled in, 'other' was counted only once per patient. }\end{array}$
\end{tabular}


Figure 2. Recommended and/or prescribed medication for acute rhinosinusitis on day 0

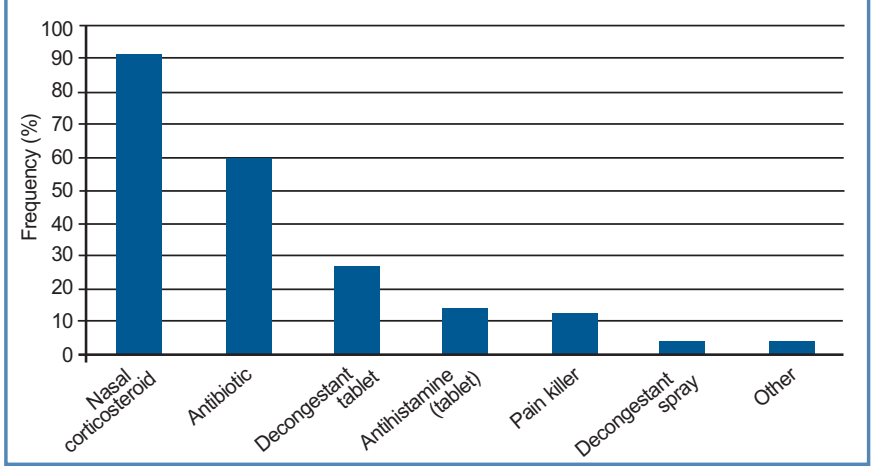

Figure 3. Self-reported health status (EQ-5D ${ }^{\mathrm{m}}$ ) of patients with acute rhinosinusitis on days 0 and 15

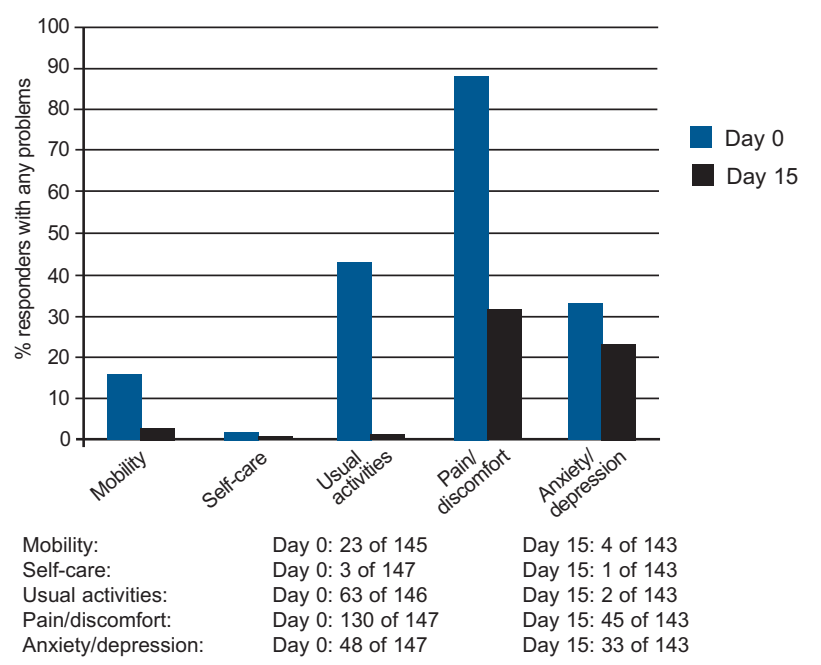

was reported by $10.9 \%$, and $10.9 \%$ were also unable to perform their usual activities. Both dimensions showed improvement on day 15 when $31.5 \%$ of patients reported moderate/extreme pain and $1.4 \%$ reported having problems with usual activities. Self-care was the dimension least affected by acute rhinosinusitis (Figure 3).

Analysis of the EQ-5DTM data based on MSS symptom severity classes indicated that patients with higher MSS experienced extreme problems in the EQ-5D ${ }^{\mathrm{TM}}$ dimensions, mainly pain/discomfort and usual activities, to a greater extent than patients with lower MSS.

The mean (SD) VAS score improved from 58.7 (18.9) on day 0 to 79.5 (19.1) on day 15 (Table 3). The Pearson correlation coefficient between VAS and MSS on day 15 was -0.37 . The Pearson correlation coefficient between VAS and MSS for the individual item scores on day 15 was -0.28 for facial pain or tenderness on palpation, -0.32 for sinus headache and -0.37 for nasal congestion/stuffiness.

\section{Costs (direct and indirect costs)}

The mean total cost for one episode of acute rhinosinusitis was 10,260 SEK (€1,102 at May 2011, 1 SEK $=€ 0.11)$, of which
Table 3. Change in VAS in patients with rhinosinusitis from day 0 to day 15

\begin{tabular}{lll} 
Day & No. of patients & Mean (SD) VAS \\
\hline Day 0 & 146 & $58.7(18.9)$ \\
\hline Day 15 & 143 & $79.5(19.1)$ \\
\hline Day 15 - Day 0 & 142 & $21.0(22.6)$ \\
\hline \multicolumn{2}{l}{ SD=standard deviation, VAS=visual analogue scale. }
\end{tabular}

Table 4. Costs of an episode of acute rhinosinusitis

\begin{tabular}{|c|c|c|c|}
\hline Statistic & Direct cost & Indirect cost & Total cost \\
\hline No. of observations & 143 & 143 & 143 \\
\hline Mean (SD) & $2,478(1,256)$ & $7,781(9,639)$ & $10,260(10,104)$ \\
\hline Median & 1,981 & 3,456 & 5,993 \\
\hline Q1, Q3 & $1,867,2,438$ & $0,13,943$ & $2,325,16,166$ \\
\hline Min, Max & $1,614,10,099$ & $0,44,258$ & $1,728,54,357$ \\
\hline \multicolumn{4}{|c|}{ Unit=SEK; 1 SEK $=€ 0.11$ (May 2011). } \\
\hline \multicolumn{4}{|c|}{$\begin{array}{l}\text { Direct cost is the sum of costs for doctor visit and institutional care, travel to } \\
\text { doctor's visit, use of medications. Indirect cost is the sum of costs for fall in } \\
\text { productivity (derived from employment status and absence due to illness). } \\
\text { Total cost is the sum of direct and indirect costs. }\end{array}$} \\
\hline \multicolumn{4}{|l|}{$\mathrm{SD}=$ standard deviation } \\
\hline
\end{tabular}

mean direct costs were 2,478 SEK (€266) (Table 4). The interindividual variability in indirect costs was large (minimum 0 and maximum 44,258 SEK $(€ 4,752))$.

There was no trend in direct, indirect or total costs based on MSS symptom severity classes. Mean total costs ranged from 9,663 SEK $(€ 1,037)$ for low severity (MSS 5-6) to 10,154 SEK $(€ 1,090)$ for high severity (MSS 10-12).

The Pearson correlation coefficients between direct, indirect and total costs and MSS were $0.00,0.11$ and 0.11 , respectively, on day 0 , and $0.18,0.11$ and 0.13 , respectively, on day 15 .

\section{Discussion}

\section{Main findings}

In this observational study in primary care, nine out of 10 adult patients with acute rhinosinusitis showed significant improvement in symptoms 15 days after a visit to a primary care physician where patients were treated according to local practice, and $91 \%$ of patients were recommended and/or prescribed intranasal corticosteroids.

As the diagnosis 'acute rhinosinusitis' does not exist in the official Swedish registry of diagnoses, based on WHO International Classification of Diseases (ICD-10), it was not possible to perform a retrospective or prospective registry study in this case. We thus needed to perform a prospective observational study to collect data.

The study design was therefore based on the $\mathrm{EP}^{3} \mathrm{OS} 2007$ recommendations for study definitions of acute rhinosinusitis and outcomes in primary care. ${ }^{4,5}$ The inclusion criteria were based on data from an earlier clinical study, ${ }^{10}$ international guidelines ${ }^{4,5}$ and Swedish clinical practice. This approach tried to exclude 
'common colds' by excluding patients with a symptom duration shorter than 7 days and an M SS $<5$, as well as excluding severe acute rhinosinusitis by not including patients with MSS $>12$ and by applying the exclusion criteria.

The results from the analyses of the primary endpoint showed a very high proportion of responders, with about $90 \%$ of patients demonstrating a clinically relevant improvement during the time period investigated. The results further showed that there was good symptom relief within the studied time period, as mean MSS decreased from 8.4 at baseline to 1.9 on day 15 . This was a greater improvement than seen in the randomised placebo-controlled clinical study by M eltzer et al. in which MSS was used as a primary endpoint to compare mometasone furoate nasal spray with amoxicillin and placebo. ${ }^{10}$ However, it should be noted that our study is not easily comparable with the study by Meltzer et al. as it was observational and was not designed to compare efficacy and safety of treatments for acute rhinosinusitis. Furthermore, MSS was used in a different way in our study from that in the study by M eltzer et al.

The treatments prescribed and used during the study period consisted mainly of intranasal corticosteroids and/or antibiotics. The finding of the surprisingly high use of intranasal steroids is an indication of a change in the clinical treatment of acute rhinosinusitis in primary care, consistent with the EP ${ }^{3} \mathrm{OS}$ evidence-based guidelines. ${ }^{4,5}$

The slight decrease in the number of patients using nasal corticosteroids and the corresponding increase in patients using antibiotics during the 15 days of study remains to be explained. One theory could be that some patients did not respond to initial nasal steroid treatment and were switched to antibiotics. Interpretation of findings in relation to previously published work

A comparison of the results from the current study with a recently published French survey of 397 general practitioners (GPs), summarising data from 1,585 patients, showed that the use of intranasal steroids was higher $(91 \%$ vs. $38.7 \%)$ in our study and the use of oral antibiotics was lower $(60 \%$ vs. $86.5 \%)^{19}$ However, the study populations differed in characteristics as the French questionnaire survey was based on physician diagnosis of acute maxillary sinusitis with signs of a bacterial infection. A recent study performed in the Netherlands using questionnaires sent to GPs showed that oral antibiotics were prescribed by approximately one-third of the practitioners for mild and moderate acute rhinosinusitis. ${ }^{15}$ In the current study, we found that antibiotic treatment was common, despite national programmes to reduce its use. ${ }^{20}$ The most recent Cochrane update emphasised that antibiotics have a limited treatment effect in acute rhinosinusitis and stated that most cases will resolve without antibiotics within 2 weeks. ${ }^{21}$ Our interpretation of the data is that, in contrast to medical evidence and recent guidelines, there still seems to be a general view among GPs that mild to moderate acute rhinosinusitis is the result of a bacterial infection.
In the Dutch study, decongestants were the most commonly prescribed treatments for both mild $(91 \%)$ and moderate $(83 \%)$ acute rhinosinusitis and were the first choice treatment in both cases. ${ }^{15}$ The use of decongestants was approximately three times more common than in our study, which is interesting as the evidence level is low for the efficacy of decongestants in mild to moderate disease. ${ }^{4,5}$ However, only one-third of the GPs in the Dutch study considered prescribing intranasal corticosteroids in mild or moderate acute rhinosinusitis.

The quality of life measure chosen by us was a generic and short validated method, the EQ-5D $\mathrm{D}^{\mathrm{Tm}}$. As this is a noninterventional study, any 'intervention' (including time for filling out questionnaires) outside common clinical practice, taking an unreasonably long time for the patient (or the primary care centre) could have jeopardised the approval by the Ethics Committee.

The data suggest a high burden of acute rhinosinusitis on quality of life parameters, an area that has not so far been well studied. At baseline, pain/discomfort was reported by $88.4 \%$ of the patients and problems with usual activities by $43.2 \%$. Both dimensions showed improvement on day 15 . Investigation of the correlation between MSS and quality of life showed that increased MSS to a large extent gave worse problems in the EQ$5 D^{T M}$, mostly pain/discomfort and usual activities. The mean health status measured using the VAS score improved from day 0 to day 15 and there was some correlation between EQ-5D ${ }^{\mathrm{TM}}$, VAS and MSS on day 15. The data are in line with the results from a randomised placebo-controlled study by Bachert and M eltzer which demonstrated significant improvement in diseasespecific quality of life among effectively treated patients with acute rhinosinusitis. ${ }^{16}$ However, the SNOT-20 questionnaire used in that study was originally not developed for acute rhinosinusitis. Quality of life deserves further investigation and is a recommended assessment to be included in clinical studies of acute rhinosinusitis. ${ }^{22}$

The mean total cost for an episode of acute mild to moderate rhinosinusitis in patients seeking primary care was 10,260 SEK (approximately $€ 1,102$ at May 2011). The direct costs (medications, visits to the physician) constituted only about $25 \%$ of the total costs, indicating that the main costs for acute rhinosinusitis are due to loss in productivity (indirect costs). There was a large difference between mean and median numbers in the cost analysis, and a few patients reported very high costs. In cost of illness studies it is not uncommon to find large variability in patient level cost estimates. ${ }^{23,24}$ When the cost was correlated to the MSS, some correlation between direct, indirect and total costs and MSS on day 15 could be shown. There was also some correlation for indirect and total costs with MSS on day 0 .

This is the first observational study in Scandinavia to address costs for acute rhinosinusitis in primary care. A recent Swedish questionnaire study of allergic rhinitis and the common cold used a similar method to estimate productivity loss and found a mean productivity loss of $€ 653$ per worker per year, adding up to an 
indirect cost of $€ 2.7$ billion for society as a whole. ${ }^{25}$ Although acute rhinosinusitis is arguably less prevalent than allergic rhinitis and the common cold, the high cost per episode suggests that acute rhinosinusitis has a considerable financial impact on society. Limitations and strengths of this study

Weaknesses of the study are the recognised problems of observational studies as well as, in our case, a small population size and the use of a non-validated productivity, healthcare utilisation and treatment questionnaire. Having a pharmaceutical company as a sponsor of the study could potentially influence the treatment choices, even though local Swedish guidelines and European legislation on conduct of non-interventional studies were followed.

On the other hand, the strengths of our study are the primary care 'real-life' setting and the prospective design with independent follow-up. Furthermore, we used validated questions on quality of life (EQ-5D ${ }^{\mathrm{TM}}$ ) and symptom score (MSS).

\section{Conclusions}

In conclusion, with a pharmacological treatment pattern dominated by intranasal corticosteroids, a high proportion of responders and good symptom relief were seen within the study time period. In addition, our data suggest a high burden of acute rhinosinusitis on quality of life and also a high cost for society, two areas that have not been well studied in Europe.

\section{Handling editor Osman Mohammed Yusuf Statistical review Gopal Netuveli}

Acknowledgements The authors thank Patrick Svarvar (Merck) for input to the study design, Catarina Jansson-Blixt (TFS Sweden) for statistical support, Sari von Reedtz (MSD) for supporting the study report, Johanna Andlin (MSD) for supporting the study protocol and Hanna Liedman (TFS Sweden) for editorial support. The authors also thank all the investigators in the study; Rickard Ekesbo, Dalby; Ines Vinge, Lindingö; Bo Polhem, Uddevalla; Ingrid Johansson, Fjugesta; Tomas Lindskog, Växjö; Christer Dahlqvist, Limhamn; Per Hellke, Göteborg; Kjell Larsson, Arvidsjaur; Anne-Sofie Lindberg, Bro; Maria Papachristou Örebro; and Luisa Escuder, Bromma, all in Sweden.

Conflicts of interest BS and P Odebäck have received honoraria for educational activities from MSD, GSK and AstraZeneca. PS has received grants for studies and honoraria for educational activities from MSD, GSK, AstraZeneca and Novartis. P Olsson was employed by MSD during the conduct of the study and is currently employed by Boehringer-Ingelheim. $J \mathrm{~L}$ is an employee of MSD and owns stock options and shares in Merck \& Co. BS is an Associate Editor of the PCRJ, but was not involved in the editorial review of, nor the decision to publish, this article. Contributorship All authors contributed equally to this paper. Funding MSD (Sweden) AB funded this study, as well as the editorial support by Hanna Liedman.

\section{References}

1. Lindbaek M. Acute sinusitis: guide to selection of antibacterial therapy. Drugs 2004;64(8):805-19. http://dx.doi.org/10.2165/00003495-200464080-00002

2. Slavin RG, Spector SL, Bernstein IL, et al. The diagnosis and management of sinusitis: a practice parameter update. J Allergy Clin Immunol 2005;116(6 Suppl):S13-S47. http://dx.doi.org/10.1016/j.jaci.2005.09.048

3. Sande MA and Gwaltney JM. Acute community-acquired bacterial sinusitis: continuing challenges and current management. Clin Infect Dis 2004;39(Suppl 13):S151-8. http://dx.doi.org/10.1086/421353.

4. Fokkens W, Lund V, Mullol J. European position paper on rhinosinusitis and nasal polyps. Rhinol Suppl 2007;20:1-136.

5. Thomas M, Yawn BP, Price D, Lund V, Mullol J, Fokkens W. EPOS Primary Care Guidelines: European position paper on the primary care diagnosis and management of rhinosinusitis and nasal polyps 2007 - a summary. Prim Care Respir J 2008;17(2):79-89. http://dx.doi.org/10.3132/pcrj.2008.00029.

6. Hickner JM. Acute rhinosinusitis: a diagnostic and therapeutic challenge. J Fam Pract 2001;50(1):38-40.

7. Piccirillo JF. Clinical practice. Acute bacterial sinusitis. N Engl J M ed 2004;351(9):902 10. http://dx.doi.org/10.1056/NEJMcp035553.

8. Anon JB, Jacobs MR, Poole MD, et al. Antimicrobial treatment guidelines for acute bacterial rhinosinusitis. Otolaryngol Head Neck Surg 2004;130(1 Suppl):1-45. http://dx.doi.org/10.1016/j.otohns.2003.12.003

9. Stalman W, van Essen GA, van der Graaf Y, de Melker RA. The end of antibiotic treatment in adults with acute sinusitis-like complaints in general practice? A placebo-controlled double-blind randomized doxycycline trial. $\mathrm{Br} J$ Gen Pract 1997;47(425):794-9.

10. Meltzer EO, Bachert C, Staudinger H. Treating acute rhinosinusitis: comparing efficacy and safety of mometasone furoate nasal spray, amoxicillin, and placebo. J Allergy Clin Immunol 2005;116(6):1289-95.

http://dx.doi.org/10.1016/ j.jaci.2005.08.044.

11. Young J, De Sutter A, Merenstein D, et al. Antibiotics for adults with clinically diagnosed acute rhinosinusitis: a meta-analysis of individual patient data. Lancet 2008;371(9616):908-14. http://dx.doi.org/10.1016/S0140-6736(08)60416-X.

12. Felmingham D, Reinert RR, Hirakata $Y$, Rodloff $A$. Increasing prevalence of antimicrobial resistance among isolates of Streptococcus pneumoniae from the PROTEKT surveillance study, and comparative in vitro activity of the ketolide, telithromycin. J Antimicrob Chemother 2002;50(Suppl S1):25-37.

13. Ashworth M, Charlton J, Ballard K, Latinovic R, Gulliford M. Variations in antibiotic prescribing and consultation rates for acute respiratory infection in UK genera practices 1995-2000. Br J Gen Pract 2005;55(517):603-08.

14. Berg 0, Carenfelt $C$, Kronvall G. Bacteriology of maxillary sinusitis in relation to character of inflammation and prior treatment. Scand J Infect Dis 1988;20(5):511-16. http://dx.doi.org/10.3109/00365548809032499

15. Hoffmans R, Schermer T, van Weel C, Fokkens W. Management of rhinosinusitis in Dutch general practice. Prim Care Respir J 2011;20(1):64-70. http://dx.doi.org/10.4104/pcrj.2010.00064.

16. Bachert C, M eltzer EO. Effect of mometasone furoate nasal spray on quality of life of patients with acute rhinosinusitis. Rhinology 2007;45(3):190-6.

17. Revicki D, Margolis M, Thompson C, M eltzer E, Sandor D, Shaw J. Major Symptom Score Utility Index for patients with acute rhinosinusitis. Am J Rhinol Allergy 2011;25(3):99-106. http://dx.doi.org/10.2500/ajra.2011.11.3575.

18. Rabin R, de Charro F. EQ-5D: a measure of health status from the EuroQol Group. Ann Med 2001;33(5):337-43. http://www.euroqol.org. http://dx.doi.org/10.3109/07853890109002087

19. Klossek JM, Mesbah K. Presentation and treatment of acute maxillary sinusitis in general practice: a French observational study. Rhinology 2011;49(1):84-9.

20. Mölstad S, Erntell M, Hanberger $H$, et al. Sustained reduction of antibiotic use and low bacterial resistance: 10-year follow-up of the Swedish Strama programme. Lancet Infect Dis 2008;8(2):125-32. http://dx.doi.org/10.1016/S1473-3099(08)70017-3.

21. Ahovuo-Saloranta A, Borisenko OV, Kovanen N, et al. Antibiotics for acute maxillary sinusitis. Cochrane Database Syst Rev 2008;(2):CD000243. http://dx.doi.org/10.1002/14651858.CD000243.pub2.

22. Meltzer EO, Hamilos DL, Hadley JA, et al. Rhinosinusitis: establishing definitions for clinical research and patient care. J Allergy Clin Immunol 2004;114(6 suppl):155-212. http://dx.doi.org/10.1016/j.jaci.2004.09.029.

23. Jansson SA, Rönmark E, Forsberg B, Löfgren C, Lindberg A, Lundbäck B. The economic consequences of asthma among adults in Sweden. Respir Med 2007;101(11):2263-70. http://dx.doi.org/10.1016/j.rmed.2007.06.029.

24. Gendo K, Sullivan SD, Lozano P, Finkelstein JA, Fuhlbrigge A, Weiss KB. Resource costs for asthma-related care among pediatric patients in managed care. Ann Allergy Asthma Immunol 2003;91(3):251-7. http://dx.doi.org/10.1016/S1081-1206(10)63526-0.

25. Hellgren J, Cervin A, Nordling S, Bergman A, Cardell LO. Allergic rhinitis and the common cold - high cost to society. Allergy 2010;65(6):776-83. http://dx.doi.org/10.1111/j.1398-9995.2009.02269.x.

Available online at http://w w w.thepcrj.org 


\section{QUESTIONNAIRE ON SYMPTOMS OF ACUTE RHINOSINUSITIS}

Patient number:

\begin{tabular}{|l|l|}
\hline Day 0 & Date: 200_- $\frac{}{\text { Month }}-$ Day \\
Day $15(+/-2)$ & \\
\hline
\end{tabular}


Appendix 1. MSS questionnaire continued

\section{PLEASE SEE THE INSTRUCTIONS}

\begin{tabular}{|l|llll|}
\hline \multicolumn{7}{|l|}{ How have you been affected by the following symptoms during the last 12 hours? } \\
\hline Facial pain, pressure or tenderness on palpation & $0 \square$ & $1 \square$ & $2 \square$ & $3 \square$ \\
\hline Sinus headache & $0 \square$ & $1 \square$ & $2 \square$ & $3 \square$ \\
\hline Rhinorrhea & $0 \square$ & $1 \square$ & $2 \square$ & $3 \square$ \\
\hline Post-nasal drip & $0 \square$ & $1 \square$ & $2 \square$ & $3 \square$ \\
\hline Nasal congestion/stuffiness & $0 \square$ & $1 \square$ & $2 \square$ & $3 \square$ \\
\hline
\end{tabular}




\section{INSTRUCTIONS FOR:}

\section{QUESTIONNAIRE ON SYMPTOMS OF ACUTE RHINOSINUSITIS}

- Use a blue/black ball point pen

- Write legibly

- Tick only one box that corresponds to symptom severity

Rhinosinusitis symptoms

Facial pain, pressure, tenderness on palpation over the paranasal sinuses

$0=$ None

$1=$ Mild

No symptom evident

$2=$ Moderate

Symptoms easily tolerated

$3=$ Severe

Moderate symptoms that are bothersome but tolerable

Severe symptoms hard to tolerate; causes interference with activities of daily living and/or sleeping

Sinus headache (forehead, eye-region and temple)

$0=$ None

No headache

$1=$ Mild

Mild headache, allowing normal activity

$2=$ Moderate

Disturbing but not prohibiting normal activity, bed rest is not

$3=$ Severe necessary Severe headache; normal activity has to be discontinued, bed rest may be necessary

\section{Rhinorrhea (nasal discharge/runny nose)}

$$
\begin{aligned}
& 0=\text { None } \\
& 1=\text { Mild } \\
& 2=\text { Moderate } \\
& 3=\text { Severe }
\end{aligned}
$$

No runny nose

Snuffles; occasional wiping and/or nose blowing

Frequent wiping and/or nose blowing; frequently interrupts talking, is annoying

Very frequent wiping and/or nose blowing. Very annoying and causes interference with activities of daily living and/or sleeping.

\section{Post-nasal drip (mucus in the throat)}

$0=$ None

No post-nasal drip

$1=$ Mild

Snuffles, occasional throat clearing

$2=$ Moderate

Frequent throat clearing; frequently interrupts talking, is annoying

$3=$ Severe

Very frequent throat clearing; constantly interrupts talking and causes interference with activities of daily living and/or sleeping

\section{Nasal congestion/stuffiness}

$$
\begin{aligned}
& 0=\text { None } \\
& 1=\text { Mild } \\
& 2=\text { Moderate } \\
& 3=\text { Severe }
\end{aligned}
$$

No congestion, or same as before

Slight block in one or both nostrils; nasal air flow somewhat impeded and annoying, no or only infrequent mouth breathing Moderate block in one or both nostrils, nasal air flow noticeably impaired, is annoying, frequent mouth breathing Both nostrils completely blocked, very annoying, need to breath through the mouth all or almost all of the time 


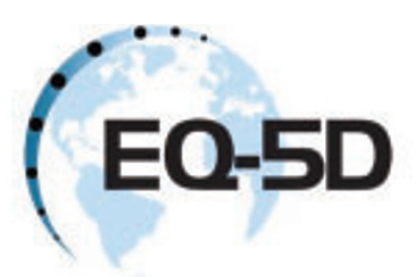

Health Questionnaire

English version for the UK

(validated for Ireland)

(1) 1990 EuroQol Group EQ-50 is a trade mark of the EuroQol Group 
By placing a tick in one box in each group below, please indicate which statements best describe your own health state today.

\section{Mobility}

I have no problems in walking about

I have some problems in walking about

I am confined to bed

\section{Self-Care}

I have no problems with self-care

I have some problems washing or dressing myself

I am unable to wash or dress myself

Usual Activities (e.g. work, study, housework, family or leisure activities)

I have no problems with performing my usual activities

I have some problems with performing my usual activities

I am unable to perform my usual activities

\section{Pain/Discomfort}

I have no pain or discomfort

I have moderate pain or discomfort

I have extreme pain or discomfort

\section{Anxiety/Depression}

I am not anxious or depressed

I am moderately anxious or depressed

I am extremely anxious or depressed 
To help people say how good or bad a health state is, we have drawn a scale (rather like a thermometer) on which the best state you can imagine is marked 100 and the worst state you can imagine is marked 0 .

We would like you to indicate on this scale how good or bad your own health is today, in your opinion. Please do this by drawing a line from the box below to whichever point on the scale indicates how good or bad your health state is today.

Your own

health state

today

\author{
health state
}

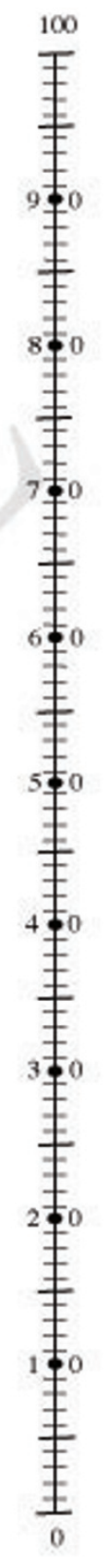

Worst imaginable health state 
Questionnaire for patients with acute sinusitis

Patient number: $-\ldots-\ldots$

Date of visit: Year 20__ Month___ Day

If you feel that anything in the questionnaire is unclear, or if you do not understand what it refers to, please ask a doctor or nurse for help. 
(By sinusitis is meant acute sinusitis)

\section{Doctor visit and institutional care}

1. Have you during the last week visited a doctor or other caregiver as a result of your sinusitis?

$\mathrm{a} \square$ yes $\quad \mathrm{b} \square$ no (go to question 3)

2. If yes, which of the following doctors or other caregivers have you visited? More than one alternative may be selected

a $\square$ ear, nose and throat doctor, please state number of visits .....

b $\square$ general practitioner, community health clinic, please state number of visits .....

c $\square$ doctor's urgent care clinic, please state number of visits .....

d $\square$ doctor emergency room, please state number of visits .....

e $\square$ district nurse or other nurse, please state number of visits .....

f $\square$ other caregiver, please state number of visits .....

3. Have you during the last week been admitted to a hospital as a result of your sinusitis?
a $\square$ yes
b $\square$ no (go to question $\mathbf{5})$

4. If yes, how many nights in total were you in the hospital as a result of your sinusitis or other infection or inflammation in your respiratory passages during the past week?

Number of nights: 


\section{Travel to doctor's visit}

5. How many kilometers have you travelled today from your home/work to make this visit to the doctor?
a $\square 0$ - 2 kilometers
$\mathrm{b} \square 2$ - 4 kilometers
c $\square 4$ - 6 kilometers
$\mathrm{d} \square 6$ or more kilometers

6. What was your primary means of transportation today, in order to make this visit to the doctor?
a $\square$ Bicycled/walked
$\mathrm{b} \square \mathrm{Car}$
c $\square$ Bus/train
$\mathrm{d} \square$ Other

\section{Employment status and absence due to illness}

7. What is your primary employment status?
a $\square$ Work full-time
$\mathrm{b} \square$ Work part-time
c $\square$ Study full-time
$\mathrm{d} \square$ Study part-time
e $\square$ Other (e.g. unemployed, parental leave, disability retired, retired, on sick leave for reason other than sinusitis)

8. Have you been absent from your work/studies as a result of sinusitis during the past week?
a $\square$ yes
$\mathrm{b} \square$ no (go to question 10)

9. If yes, how many days during the past week have you reported absent due to illness from work/studies as a result of sinusitis?

Number of days:

10. Have you during the past week had problems with sinusitis and still worked/studied?

a $\square$ yes $\quad \mathrm{b} \square$ no (go to question 13) 
11. If yes, estimate how many days during the past week you have had problems with sinusitis and still worked/studied.

Number of days:

12. How would you rate your ability to perform at work/studies during those days you have had problems with sinusitis and still worked/studied? $0=$ no ability $100=$ complete ability to perform

(mark an X on the scale)

\begin{tabular}{ccccc}
\hline & $\mid$ & $\mid$ & \\
0 & 25 & 50 & 75 & 100
\end{tabular}

\section{Use of medications for sinusitis}

13. Have you during the past week used any medication/natural remedy/selftreatment as a result of your sinusitis?
$\mathrm{a} \square$ yes
$\mathrm{b} \square$ no

14. If yes, which of the following preparations have you used?

Mark an X for the preparations you used (several alternatives can be stated)

$\begin{array}{ll}\mathrm{a} \square \text { Antibiotic tablets/liquid } & \text { Number of days ..... } \\ \mathrm{b} \square \text { Cortisone nasal spray/drops/powder } & \text { Number of days ..... } \\ \mathrm{c} \square \text { Decongestant tablets } & \text { Number of days ..... } \\ \mathrm{d} \square \text { Decongestant spray/pipette } & \text { Number of days ..... } \\ \mathrm{e} \square \text { Allergy tablets/antihistamine tablets/ } & \text { Number of days ..... }\end{array}$ liquid/dissolving

f $\square$ Pain-relief tablets/liquid Number of days .....

$\mathrm{g} \square$ Other medication/natural remedy

indicate type Number of days .....

indicate type Number of days ..... 